\title{
CLINICAL EXPERIENCES WITH KETALAR
}

\author{
W. E. Spoerel, M.D., F.R.C.P.(C) and Patricia F. Kandel, M.D."
}

Ketalar (CI-581) Is a new parenteral anaesthetic agent (Figure 1). Unlike other parenteral agents it produces the unique effect of unconsciousness without loss of muscle tone resembling catalepsy, profound analgesia, and amnesia which has been described by Corssen as "dissociative anaesthesia". ${ }^{1}$ Its special features are the maintenance of an airway and laryngeal reflexes, the lack of respiratory and cardiovascular depression, and its wide margin of safety.

This clinical trial with Ketalar includes 146 children aged four days to 15 years and 20 adults.

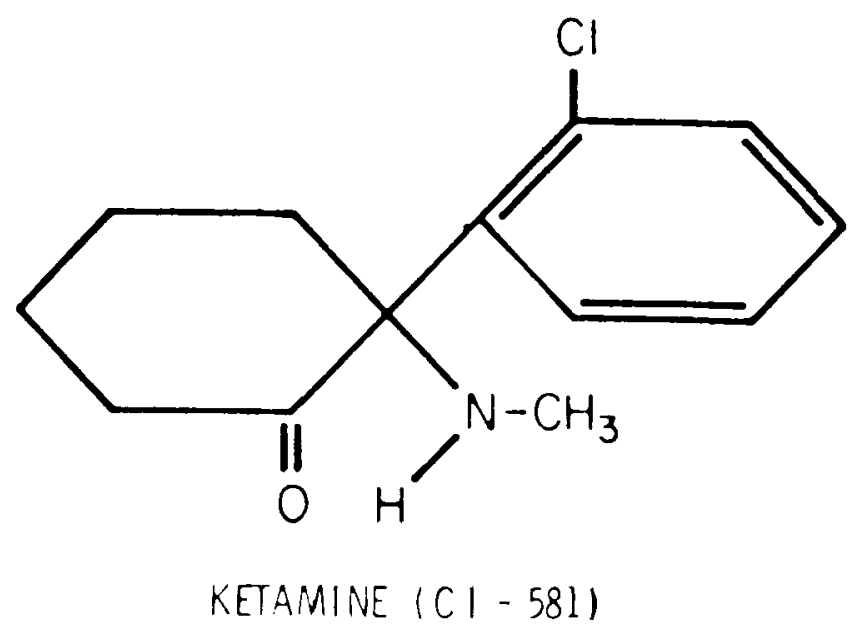

Figure 1

\section{Children}

Ketalar was the sole anaesthetic agent used in 136 children. In the remaining ten cases it was used for induction only or as the main agent in a conventional type of anaesthesia. In six children the drug alone did not produce satisfactory surgical conditions and it was necessary to supplement it with conventional anaesthetic drugs.

The indications for Ketalar as the sole agent in children were similar to those reported by Corssen et al. ${ }^{2}$ (Table I).

Orthopaedics. In orthopaedic surgery Ketalar proved very satisfactory for closed reductions of fractures. Usually one injection sufficed for manipulation and application of cast. Also open reductions and tendon surgery were carried out with Ketalar alone.

"Department of Anaesthesia, University of Western Ontario, London, Canada. 
TABLE I

Surgical Procedures using Ketalar as the Sole Agent FOR CHILDREN

\begin{tabular}{|c|c|c|}
\hline & Number of cases & Unsatisfactory \\
\hline $\begin{array}{l}\text { Orthopaedics } \\
\text { Closed reduction } \\
\text { Tendon surgery } \\
\text { Others }\end{array}$ & $\begin{array}{r}21 \\
10 \\
2\end{array}$ & \\
\hline $\begin{array}{l}\text { Plastic surgery } \\
\text { Burns } \\
\text { Lacerations } \\
\text { Biopsies, etc. }\end{array}$ & $\begin{array}{r}15 \\
9 \\
7\end{array}$ & \\
\hline $\begin{array}{l}\text { Urology } \\
\text { Cystoscopy } \\
\text { Circumcision }\end{array}$ & $2 \frac{1}{7}$ & \\
\hline $\begin{array}{l}\text { Eye } \\
\text { EUA } \\
\text { Probing of tear ducts } \\
\text { Squint }\end{array}$ & $\begin{array}{r}15 \\
6 \\
1\end{array}$ & (1) \\
\hline $\begin{array}{l}\text { ENT } \\
\text { Myringotomy } \\
\text { Oesophageal dilatation } \\
\text { Endoral procedures } \\
\text { Simple mastoid }\end{array}$ & $\begin{array}{l}4 \\
1 \\
7 \\
1\end{array}$ & $\begin{array}{l}(1) \\
(1) \\
(1)\end{array}$ \\
\hline $\begin{array}{l}\text { Neurological } \\
\text { Air study } \\
\text { Cerebral angiograms } \\
\text { Removal of shunt }\end{array}$ & $\begin{array}{l}1 \\
5 \\
1\end{array}$ & (1) \\
\hline $\begin{array}{l}\text { General } \\
\text { Hernia repair }\end{array}$ & 2 & (1) \\
\hline Total & 136 & (6) \\
\hline
\end{tabular}

Plastic surgery. Ketalar offers great advantages in burn cases particularly when ill and apprehensive children require multiple anaesthetics and a quiet recovery. One such child with extensive body burns received six Ketalar anaesthetics in her hospital room. Ketalar proved useful for most plastic procedures about the face; the exception was extensive peri-oral surgery, in particular, hare lips, where conventional technique with endotracheal intubation was preferred. Although patients under Ketalar do not react to pain, small movements of the facial muscles, head and extremities do occur and are not obtunded by increased dosage. For these reasons a consistently quiet surgical field can not be guaranteed. When less extensive surgery about the lips is contemplated the presence of muscle tone and the absence of a distorting endotracheal tube are definite assets to offer the plastic surgeon.

Bleeding, brisker than usual, was noted in some plastic cases at the time of skin incision and dissection; this was initially disturbing particularly in one case of release of severe burn contractures of the neck. However, because normal haemostatic mechanisms are unimpaired, haemostasis was readily obtained in every case and we have not encountered any problems of prolonged or excessive bleeding or postoperative haematomata.

Urology. In urology, diagnostic cystoscopies, meatotomies, and circumcisions were satisfactorily performed under Ketalar. 
Ophthalmology. Ketalar has been requested by our ophthalmologists for examination of eyes and in our opinion it is the agent of choice for tear duct probings since the swallowing reflex is retained.

E.N.T. Ketalar as the sole agent produced good surgical conditions for myringotomies and simple endoral procedures such as dental extractions. Laryngoscopy can be readily performed and laryngeal reflexes observed without spasm. If topical analgesia is then applied, intubation is easily carried out. However, one attempt to go on to an oesophagoscopy was not successful. Ketalar for tonsillectomies has been discussed in a previous paper $^{3}$ and we prefer conventional techniques.

Neurological. Ketalar has been recommended for air studies and cerebral angiography. ${ }^{5}$ Because the procedure for air studies is somewhat different in our Institute we have felt safer with conventional anaesthetic techniques. Our radiologist found the picture obtained for cerebral angiography was poorer in quality than those obtained with other anaesthetic techniques due to the rapid cerebral blood flow.

\section{Preoperative preparation}

The usual preoperative fasting period was observed. Approximately one half of the children received no preoperative medication; the remainder a variety of conventional combinations including belladonna derivatives.

\section{Procedure}

Ketalar anaesthesia was induced intravenously when possible. Infants and burn cases made up most of the 31 deep intramuscular injections. The induction doses were approximately $2 \mathrm{mg} / \mathrm{kg}$ intravenously or $6 \mathrm{mg} / \mathrm{kg}$ deep intramuscularly. A similar amount was repeated when signs of lightening e.g., movement upon stimulation, became apparent; the mean time interval between doses was 12 minutes with the intravenous method and 15 to 25 minutes with intramuscular injections. However, this time interval varied considerably with the level of surgical stimulation (Figure 2).

The duration of surgical procedures ranged from 5 to 120 minutes with an average of 30 minutes (Figure 3 ).

\section{Observations during anaesthesia}

The blood pressure rose above the preoperative level an average of $18 \mathrm{~mm} \mathrm{Hg}$ systolic (range 0 to $50 \mathrm{~mm} \mathrm{Hg}$ ) and $15 \mathrm{~mm} \mathrm{Hg}$ diastolic (range 0 to $25 \mathrm{~mm} \mathrm{Hg}$ ) and the heart rate rose above the preoperative level by more than 20 to 40 per cent of cases. These changes reflect an increase in cardiac output usually produced by Ketalar ${ }^{4,6}$ and account for the problems in angiography and the brisk bleeding occasionally seen.

Respirations were judged clinically as adequate, although they were irregular on occasion and interdispersed with sighs.

\section{Intra-operative complications}

Moderate to copious salivation occurred in ten patients. It was significant 


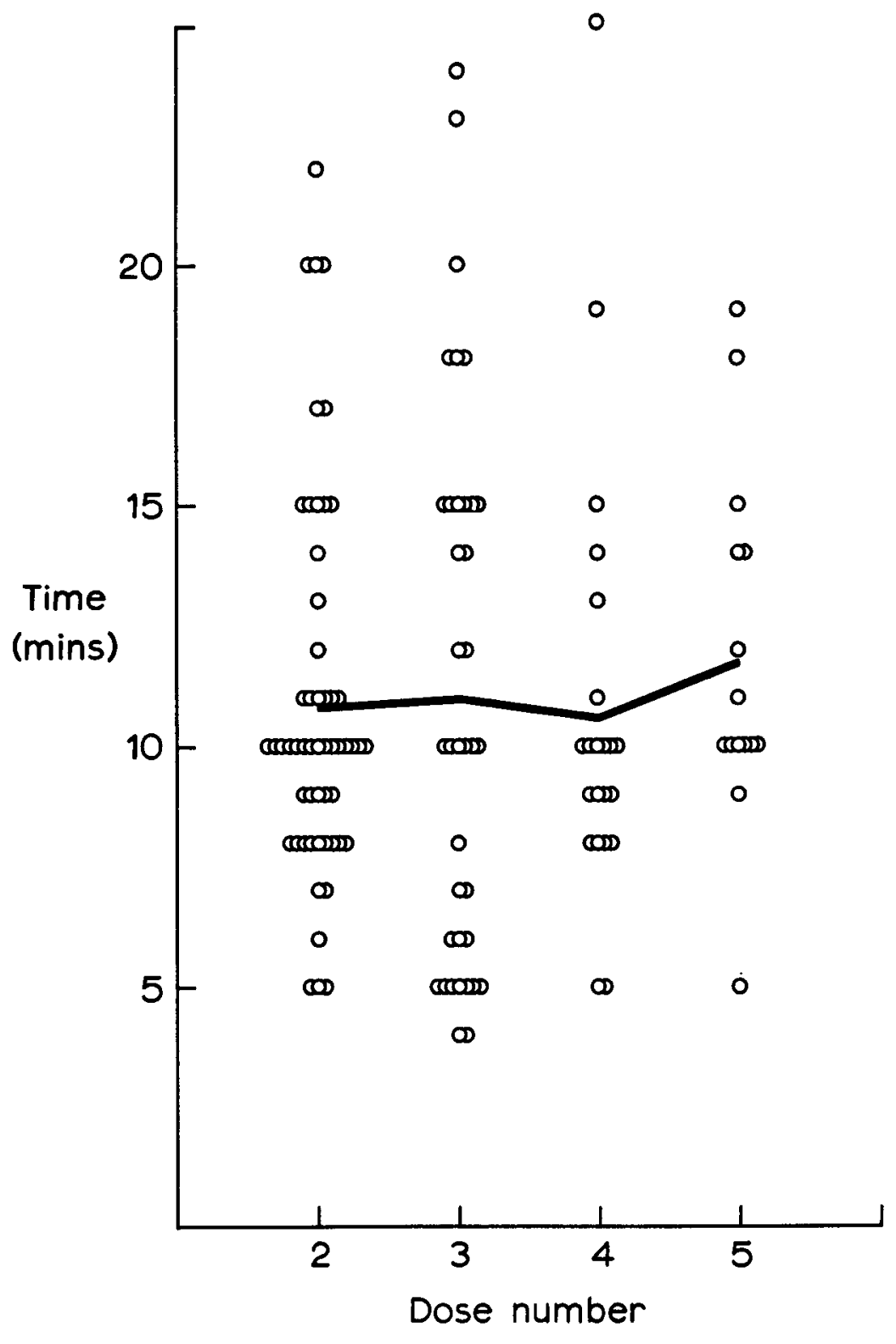

\section{KETALAR - TIME / DOSE RELATIONSHIP}

Figure 2

mainly in operations about the face. For these procedures we now give a small dose of hyoscine intravenously at the time of induction. Hyoscine was chosen because of its additional anti-emetic qualities.

There was one case of vomiting during anaesthesia. The patient was able to handle the problem and aspiration did not occur. The situation was exceptional. 


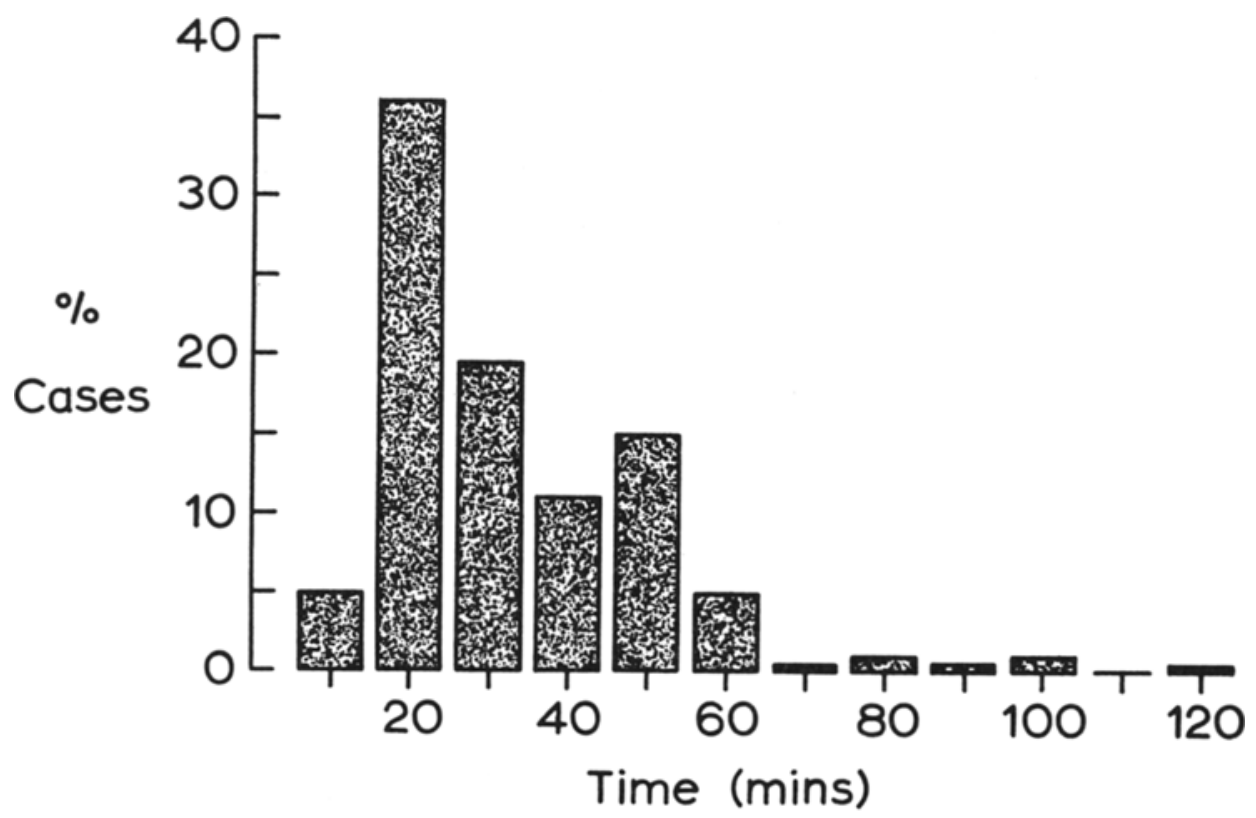

KETALAR-DURATION OF OPERATION

Figure 3

The child, who was in a body cast, had been given considerable apple juice up to two hours pre-operatively.

Myoclonic twitching occurred at times. In three cases it was quite marked and in one case occurred with each repeated injection.

In six patients the Ketalar anaesthetic originally planned had to be supplemented by conventional techniques. In four of these, a strangulated hernia, a simple mastoid operation, resection of eye muscles, and oesophagoscopy, the reason for the change was coughing, which was not controlled by further ketamine injections. Ketalar is not really suitable as a sole agent for these surgical procedures. The fifth case was anaesthesia for cerebral angiogram; intubation and ventilation were instituted to give better $x$-ray pictures. The last case was anaesthesia for plastic graft to the tongue; movements of the lips could not be sufficiently obtunded to allow the surgeon to proceed.

\section{Recovery}

Recovery time was measured as the time from the last does of Ketalar to the time the patient was ready to leave the recovery room. This ranged from 40 to 210 minutes (Figure 4). We could find no significant relationship between total dosage and recovery time. ${ }^{2}$

In the majority of cases recovery was quiet and required no extra attention from the nursing staff. 


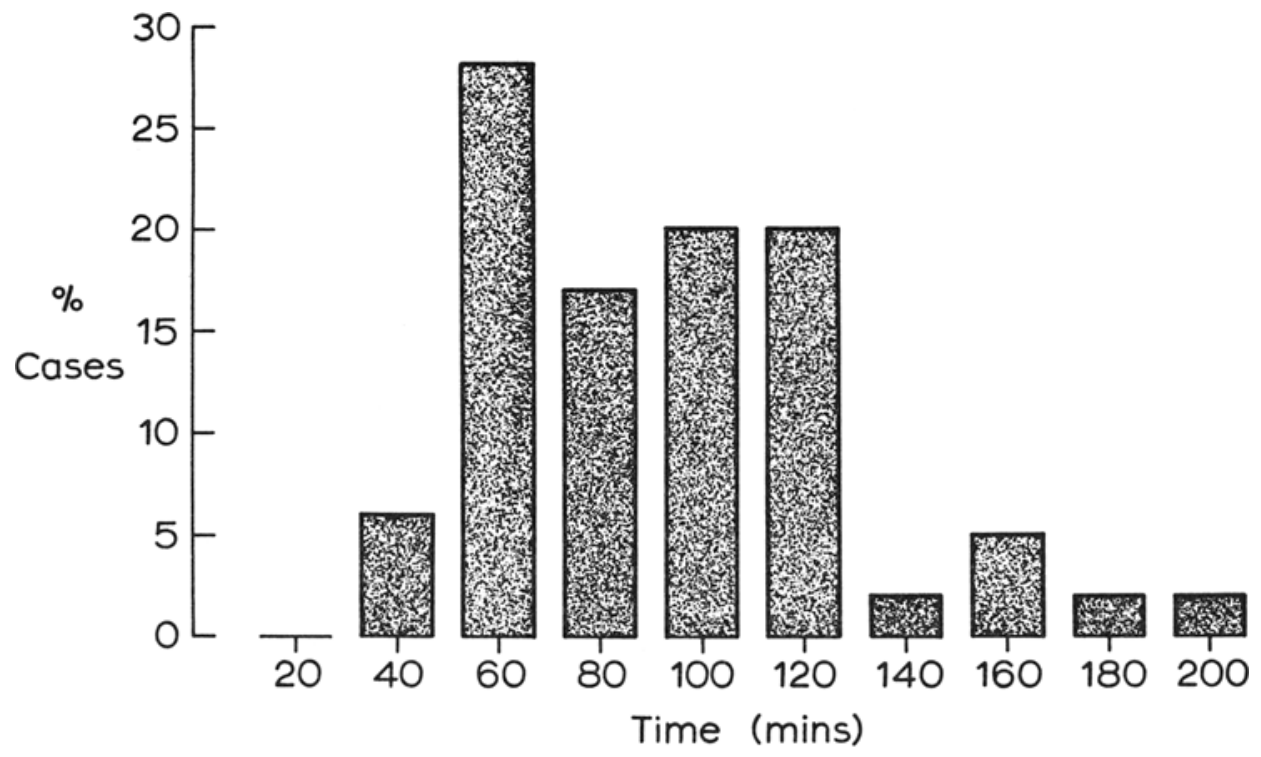

KETALAR - RECOVERY TIME

Figure 4

\section{Complications during recovery}

During the recovery period seven children exhibited bothersome salivation and eight children vomited at least once. This incidence is lower than in our tonsillectomy series, ${ }^{3}$ probably because no blood was swallowed. Shivering, which is seen with conventional anaesthesia, was observed in five cases. One child told us he dreamed and one had a transient episode of delirium during recovery.

\section{Discussion}

Ketalar is an unique new anaesthetic drug. It produces a state of unconsciousness with analgesia that is quite unlike conventional anaesthetics in many respects.

The lack of suppression of muscle tone preserves the airway and eliminates the need for intubation in selected cases. This is perhaps one of its greatest assets. The lack of cardiovascular depression is a distinct advantage in burn cases and other severe illnesses. The toxic dose is said to be ten times the therapeutic dose. The ease of administration is inspiring.

However it is not a panacea. Constant vigilance is required as with any anaesthetic. Secretions or obstruction greater than can be handled reflexly do occur. Movement indicating that surgical stimulation is being felt can occur quickly, requiring further dosage. The surgeon should understand and appreciate its advantages and be willing to accept certain apparent disadvantages, such as small movements under his hand. In some procedures, e.g., examination of the eyes, a topical anaesthetic should be applied to the eye before instrumentation. 
Its use as a sole agent for procedures producing a visceral pain is contraindicated. Recovery time may be prolonged and this can prove disadvantageous in out-patient surgery for small procedures.

\section{AdulTs}

Ketalar was used as the sole anaesthetic agent in 11 adult patients and for induction only in nine. The latter group includes two patients for whom we had planned to use Ketalar as the main agent but had to change to conventional anaesthesia because of unsatisfactory surgical conditions. The ages ranged from 19 to 81 years.

\section{Intra-operative complications}

The main problem encountered in adult patients during surgery was muscular rigidity and associated movements of the head and extremities. In one patient generalized rigidity and movements alternated almost rhythmically with intervals of relaxation. In the other the stiffness resolved into a wild restlessness about fifteen minutes after induction; $10 \mathrm{mg}$ of diazepam intravenously calmed him.

TABLE II

INTRAOPERATIVE COMPLICATIONS USING Ketalar For AdULTS

\begin{tabular}{ll}
\hline \hline Muscular rigidity & 4 \\
Hypertension $(>50 \mathrm{~mm} \mathrm{Hg}$ rise $)$ & 5 \\
Frequent extra systoles & 1 \\
Airway obstruction & 1 \\
Uneventful & 5 \\
\hline
\end{tabular}

An increase in blood pressure is commonly observed during induction and often sustained with continuing injections. For the 20 patients the average systolic rise was $34 \mathrm{~mm} \mathrm{Hg}$ (range 0 to $65 \mathrm{~mm} \mathrm{Hg}$ ) and the average diastolic rise was $20 \mathrm{~mm} \mathrm{Hg}$ (range 0 to $30 \mathrm{~mm} \mathrm{Hg}$ ). In five patients (range 20 to 53 years) the systolic blood pressure rose $50 \mathrm{~mm} \mathrm{Hg}$ or more. One patient with a healthy heart and normal electrocardiogram showed frequent extrasystoles during anaesthesia. These disappeared in the recovery room and follow-up electrocardiograms showed no abnormalities. In one patient it was necessary to support the chin to prevent airway obstruction. In only five of the eleven patients was anaesthesia uneventful and satisfactory for surgery (Table II).

\section{Postoperative complications}

Three patients had hallucinations although they were completely undisturbed in a quiet recovery room. One 40 -year-old lady told us that she had a long argument with a group of people standing around her bed although she was alone with a nurse for the entire duration of her recovery. A 53-year-old man described his experience as weird, consisting mainly of brilliant lights and colors and stated, "I know now what LSD is like." He had had several general 
TABLE III

Postoperative Complications Using KETALAR FOR ADULTS

\begin{tabular}{ll}
\hline Hallucinations & 3 \\
Headache & 2 \\
Nausea and vomiting & 3 \\
Double vision & 1 \\
Severe restlessness & 1 \\
Uneventful recovery & 5 \\
\hline
\end{tabular}

anaesthetics during the past few years but had never experienced anything like it: "I wouldn't want to have this happen every week", was his comment. Three patients vomited more than twice during recovery. Two complained of severe headache, one patient had double vision persisting over three hours. Five of the eleven patients had a completely uneventful recovery (Table III).

\section{SUMMARY}

Ketalar was used as the sole anaesthetic agent in 136 children and 11 adults and for induction of conventional anaesthesia in 10 children and 9 adults. In children Ketalar proved very suitable for a variety of orthopaedic and plastic surgery procedures, for neurological, ophthalmological, and otological examinations, and endoral procedures. In some of the indications, the use of Ketalar is advantageous as it provides a simpler and safer anaesthetic technique as compared to conventional techniques.

Under Ketalar anaesthesia, respiration appears adequate, blood pressure and pulse are usually slightly elevated, and there is a good peripheral blood flow. The protective laryngeal reflexes are retained and the airway is well maintained. A single intravenous injection provides unconsciousness and unresponsiveness for 10 to 15 minutes on the average, followed by a gradual recovery. Ketalar can be given by intramuscular injection ( 31 cases); anaesthesia occurs within 3 to 4 minutes and is slightly longer in duration. Repeat injections, either intravenous, or intramuscular will provide prolonged anaesthesia and there is little evidence of a cumulative effect with up to six repeat injections. During anaesthesia patients are not absolutely quiet. Facial movement occurs and brief periods of generalized twitching were seen occasionally. Salivation is mildly stimulated and can be readily suppressed with belladonna derivatives.

Recovery is quiet in most children. The recovery stay ranged from 40 to 210 minutes after the last injection. No disturbing hallucinations or delirium were encountered. Vomiting occurred in 6 per cent and shivering in 4 per cent of our cases.

Ketalar was on the whole less satisfactory for adult patients and the anaesthesia was unsatisfactory in some instances. During recovery, 3 of 11 patients had hallucinations and two complained of severe headache. Although our experience in adults is small we are, at present, hesitant to use Ketalar as a sole anaesthetic agent for the same indications as in children. 


\section{RÉSUMÉ}

On a étudié le kétalar comme seul agent anesthésique chez 136 enfants et 11 adultes, et comme agent d'induction à l'anesthésie générale habituelle chez 10 enfants et 9 adultes. Chez les enfants, la kétalar s'est avéré convenable pour un bon nombre d'interventions en chirurgie orthopédique et plastique, ainsi que pour des examens des yeux et des oreilles et des manœuvres endoscopiques. Dans certaines de ces indications, l'usage du kétalar est avantageux car il procure une technique d'anesthésie plus simple et plus sure par rapport aux techniques utilisées jusqu’ici.

Sous anesthésie au kétalar, la respiration semble normale, la pression sanguine et le pouls sont légèrement augmentés et le débit sanguin périphérique est bon. Les réflexes laryngés protecteurs sont maintenus et le passage de l'air est libre. Une seule injection intraveineuse produit l'inconscience et l'indifférence pour une durée de 10 à 15 minutes en moyenne, suivies d'un retour progressif à la normale. Le kétalar peut être donné par voie intramusculaire (31 cas); l'anesthésie se produit en 3 ou 4 minutes et elle est d'une durée légèrement supérieure. Des injections répétées, intraveineuses ou intramusculaires, vont procurer une anesthésie prolongée et il y a peu de manifestations d'effet cumulatif jusquà six injections successives. Durant l'anesthésie, les malades ne sont pas absolument immobiles. Il se produit quelquefois des mouvements de la face, et on observe occasionnellement de brèves périodes de convulsions généralisées. Il y a un certain degré d'hypersalivation qui peut être rapidement contrôlée par les dérivés de la belladone.

Chez la plupart des enfants, le réveil est calme. Le retour à la conscience s'effectue entre 40 et 210 minutes après la dernière injection. On n'a pas observé d'hallucinations importunes ou de délire. Six pour cent des cas ont présenté des vomissements, et 4 pour cent des frissons.

Dans l'ensemble, l'usage du kétalar a été moins encourageant chez l'adulte, et en certaines occasions, l'anesthésie n'a pas donné satisfaction. Durant le réveil, 3 de nos 11 malades ont eu des hallucinations et 2 ont souffert de céphalée sévère. Bien que notre expérience soit limitée chez les adultes, nous hésitons encore à utiliser le kétalar comme agent anesthésique unique comme nous le faisons chez les enfants.

\section{REFERENCES}

1. Domino, E. F.; Chouoff, P.; \& Conssen, G. Pharmacologic Effects of CI-581, A New Dissociative Anaesthetic in Man. J. Clin. Pharmacology and Therapeutics. 6: 279 (1965).

2. Conssen, G.; Mixasaka, M.; \& Domino, E. F. Changing Concepts on Pain Control during Surgery: Dissociative Anaesthesia with CI-581 - A Progress Report. Anesth. \& Analg. 47:746 (1968).

3. Spoerel, W. E. \& Kandel, P. F. CI-581 in Anaesthesia for Tonsillectomies in Children. Canad. Anaesth. Soc. J. 17: 172 (1970).

4. Stanley, V.; Hunt, J.; Willis, K. W.; \& Stephen, C. R. Cardiovascular and Respiratory Function with CI-581. Anesth. \& Analg. 47: 760 (1968).

5. Corssen, G.; Graves, E. H.; Comez, S.; \& Allen, R. J. Ketamine: Its Place in Anaesthesia for Neurosurgical Diagnostic Procedures. Anesth. \& Analg. 48: 181 (1969).

6. Traber, D. L. \& Wilson, R. D. Involvement of the Sympathetic Nervous System in the Pressure Response to Ketamine. Anesth. \& Analg. 48: 248 (1969). 